\title{
Formation and Taphonomy of Human Footprints in Microbial Mats of Present-Day Tidal-flat Environments: Implications for the Study of Fossil Footprints
}

\author{
Daniel Marty, ${ }^{1}$ André Strasser ${ }^{2}$ and Christian A. Meyer ${ }^{3}$ \\ ${ }^{1}$ Office de la culture, Section d' archéologie et paléontologie, Switzerland \\ ${ }^{2}$ Department of Geosciences, University of Fribourg, Fribourg, Switzerland \\ ${ }^{3}$ Naturhistorisches Museum Basel, Switzerland
}

\begin{abstract}
This study concerns the formation, taphonomy, and preservation of human footprints in microbial mats of present-day tidal-flat environments. Due to differences in water content and nature of the microbial mats and the underlying sediment, a wide range of footprint morphologies was produced by the same trackmaker. Most true tracks are subjected to modification due to taphonomic processes, leading to modified true tracks. In addition to formation of biolaminites, microbial mats play a major role in the preservation of footprints on tidal flats. A footprint may be consolidated by desiccation or lithification of the mat, or by ongoing growth of the mat. The latter process may lead to the formation of overtracks. Among consolidated or (partially) lithified footprints found on present-day tidal flats, poorly defined true tracks, modified true tracks, and overtracks were most frequently encountered while unmodified and well-defined true tracks are rather rare. We suggest that modified true tracks and overtracks make up an important percentage of fossil footprints and that they may be as common as undertracks. However, making unambiguous distinctions between poorly defined true tracks, modified true tracks, undertracks, and overtracks in the fossil record will remain a difficult task, which necessitates systematic excavation of footprints combined with careful analysis of the encasing sediment.
\end{abstract}

Keywords Human footprint, (modified) true track, overtrack, taphonomy, microbial mat, tidal flat

\section{INTRODUCTION}

The preservation of fossil vertebrate tracks in laminated sediments, in particular in tidal-flat environments, is frequently explained by the presence of microbial mats, which are thought to have covered and stabilized the tracks (e.g, Thulborn, 1990; Avanzini, 1998; Kvale et al., 2001; Freytet, 2003; Conti et al.,

Address correspondence to Daniel Marty, Office de la culture, Section d'archéologie et paléontologie, Palaeontology A16, Hôtel des Halles, P. O. Box 64, 2900 Porrentruy 2, Switzerland. E-mail: daniel.marty@palaeojura.ch
2005; Marty, 2005). It has also been suggested that undertracks commonly form in well-laminated microbially-bound sediment (Lockley, 1991). Also, the relative abundances of true tracks and undertracks in the sedimentary record (e.g., Thulborn, 1990; Lockley, 1991; Nadon, 2001; Milàn and Bromley, 2006), and the importance of correct interpretation of undertracks (Milàn and Bromley, 2006) have been discussed. Lockley (1991) spoke about tracks as traps (low energy pockets) and Paik et al. (2001) provided a model for overtrack formation by sediment accumulation (trapping) within the true track. However, overtracks and modified true tracks have not as yet been included in the "true track vs. undertrack" discussion.

Generally, only fine anatomical details such as toe marks, claw marks, or skin impressions clearly identify true tracks. Unfortunately, such details are often not recorded because the trackmaker's feet aren't suitable to leave such traces, because the animal is too heavy or too light to leave recognizable prints. Moreover, ill-defined prints are created during running or jumping, because the soles are covered with mud, because the substrate is too dry or too soft, or simply because weathering or erosion destroys the footprints (e.g., Padian and Olsen, 1984; Cohen et al., 1991; Demathieu, 1991; Nadon, 2001; Henderson, 2006; Milàn, 2006; Scott et al., 2007). Consequently, one of the major challenges of vertebrate ichnology is the unambiguous identification of true tracks and their distinction from underand overtracks and from other extramorphological features that distort true foot morphology. This is the prerequisite for meaningful ichnotaxonomical procedure, the interpretation of behavioral patterns, and for the reconstruction of the paleoenvironment.

Experimentation and modeling has contributed considerably to the understanding of the formation and characteristics of true tracks and undertracks (e.g., Peabody, 1959; Brand, 1996; Allen, 1997; Manning, 2004; Diedrich, 2005; Henderson, 2006; Milàn, 2006; Milàn and Bromley, 2006; Uchman and Pervesler, 2006; Davis et al., 2007). Nonetheless, the role of microbial mats in 
the formation and preservation of footprints on tidal flats has so far not been analyzed in greater detail.

Microbial mats are ubiquitous on modern and ancient carbonate and siliciclastic tidal flats and have been described in many classical works on peritidal environments (review in Gerdes and Krumbein, 1994; Gerdes et al., 2000; Schieber et al., 2007). Their important role in the formation and preservation of sedimentary structures is more and more recognized (e.g., Gerdes et al., 1993; Schieber et al., 2007), and they commonly bear vertebrate footprints in the Recent as well as in the geologic record. Microbial mats consist of benthic microbial communities, which are usually dominated by photosynthetic prokaryotes, particularly cyanobacteria and photosynthetic bacteria, and occasionally by eukaryotic microalgae such as diatoms (e.g., Bauld, 1984; Cohen et al., 1984; Krumbein et al., 2003; Levit and Krumbein, 2003). They grow best where they can obtain the maximum amount of sunlight and yet remain moist and in water contact (Kendall and Skipwith, 1968). Microbial mats can either agglutinate sediment particles onto their sticky mucilaginous sheaths or act as bafflers that trap sediment washed into the tangle of filaments (Demicco and Hardie, 1994). Trapping and binding is regulated by microbial activity which, in turn, may be stimulated when the mat is covered by a thin sediment layer (Burne and Moore, 1987). Microbial mats commonly display a complex vertical distribution of microbial communities that create and are adapted to specific geochemical conditions. In many cases, the sediment below a dense mat becomes anoxic (Dupraz et al., 2004).

In addition, microbial mats may quickly lithify by the precipitation of calcium carbonate (e.g., Krumbein and Cohen, 1977; Chafetz and Buczynski, 1992; Dupraz et al., 2004; Dupraz and Visscher, 2005), and consequently enhance the preservation potential of footprints and other traces. Microbial mats are particularly abundant in low latitudes where protected microtidal lagoons occur more frequently and provide varied ecospaces such as persisting thin water sheets, permanently water-filled ponds, flats subjected to daily tidal flooding, or surfaces that are water-covered only during spring-tides or storms (Gaillard et al., 1994; Gerdes and Krumbein, 1994). The products of benthic microbial communities are called "biolaminites" or "biolaminations" for the flat laminated type of stromatolites (Gerdes et al., 1991), or "biolaminoids" for less significantly laminated sediment that accumulated through the activity of microbial communities (Gerdes and Krumbein, 1987; Brehm et al., 2002).

This study addresses a number of issues concerning the formation, taphonomy, and preservation of vertebrate footprints in microbial mats of present-day tidal-flat environments: (1) Relationships between the physical properties of the microbial mat (e.g., water content, mat thickness, elasticity/plasticity) and footprint morphology; (2) Modification of footprint morphology by continued growth of the microbial mat; and (3) Consolidation of footprints by desiccation and/or lithification of the microbial mat.
These observations in modern environments are relevant for a better understanding of the taphonomy of vertebrate footprints in fossil biolaminites and for the evaluation of the relative abundances of true tracks, undertracks, and overtracks. Consequently, they help in understanding ichnotaxonomy, paleoecology, and paleoenvironment. Finally, our results help contribute to the study of fossil hominid footprint preservation especially in environments comparable to those studied here (review of fossil hominid footprint sites in Lockley et al., 2007, see also other publications of this special volume).

\section{GEOGRAPHICAL, ENVIRONMENTAL, AND CLIMATIC SETTINGS}

The data presented herein were gathered during fieldtrips to Ambergris Caye (Belize), Eleuthera Island (Bahamas), southern Tunisia, and southern Sinai (Egypt). Vertebrate tracks in microbial mats were observed in different tidal-flat environments including intertidal flats, supratidal flats and marshes, and sabkhas. These environments differ from each other mainly in respect to the thickness and nature of the microbial mats, the properties of the underlying sediment, and the water content related to tidal range and climate.

\section{Ambergris Caye (Belize)}

In February 2007, footprints were studied in Belize on Ambergris Caye SW of San Pedro Town ( $\left.87^{\circ} 59^{\prime} 00^{\prime \prime} \mathrm{W}, 17^{\circ} 54^{\prime} 11^{\prime \prime} \mathrm{N}\right)$, in mangrove swamps near South Beach, and on supratidal flats and marshes SW of the airport (Fig. 1A). Belize lies in the tropical zone, and the climate on Ambergris Caye is one of seasonally varying rainfall and evaporation rates with a drier season in winter and a rainy season in summer (Gregg et al., 1992).

The supratidal flats and marshes are topographically featureless with a maximum relief of 1-2 meters above mean sea level, locally heavily vegetated by mangroves and almost completely covered with microbial mats (Figs. 2A and 2B). Generally, these mats are smooth and flat; blistering seldom occurs. To the SW of San Pedro Town, vast surfaces have recently been subjected to deforestation (Fig. 2A), probably for new construction sites, offering perfect conditions to study footprints in dead and lithified (dolomitized) microbial mats. As theses flats were visited during the dry season, it is not known whether the microbial communities were killed by the deforestation or due to the drought. However, it is probable that new communities will install on top during the wet season.

\section{Eleuthera Island (Bahamas)}

In May 2004, footprints were studied on Eleuthera Island on a supratidal flat around the hypersaline lake No Name Pond, which is located in the northern part of the island $\left(76^{\circ} 34^{\prime} 31^{\prime \prime} \mathrm{W}\right.$, $25^{\circ} 24^{\prime} 28^{\prime \prime} \mathrm{N}$ ), about $3 \mathrm{~km} \mathrm{NW}$ of Gregory Town (Fig. 1B). Eleuthera forms part of the northeastern and windward margin of the Great Bahama Bank. It is located in the subtropical zone 


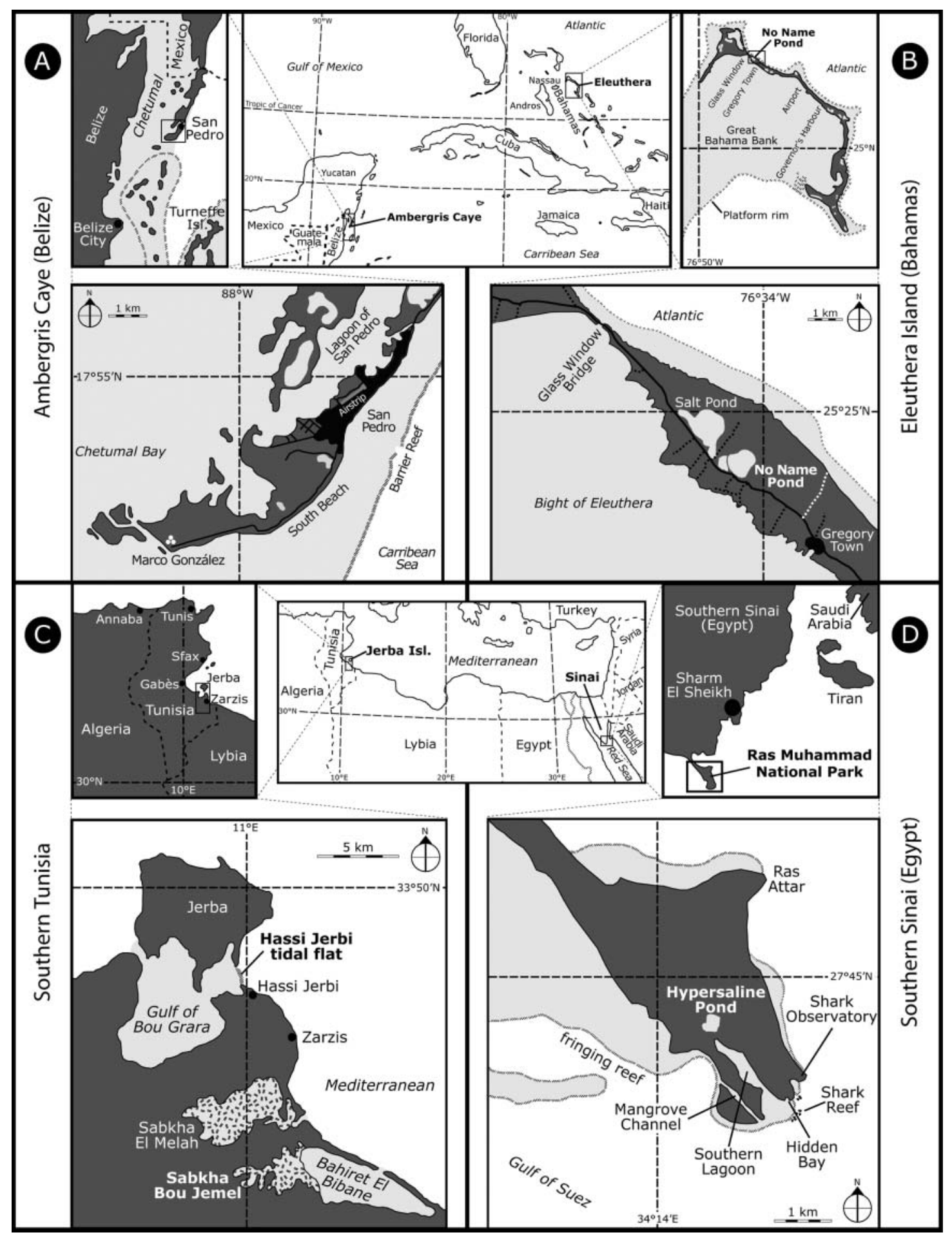

FIG. 1. Location of the studied areas. (A) Ambergris Caye SW of San Pedro Town (Belize); (B) No Name Pond on Eleuthera Island (Bahamas); (C) Hassi Jerbi tidal flat and Sabkha Bou Jemel (southern Tunisia); (D) Hypersaline Pond in the Ras Muhammad National Park (southern Sinai, Egypt).

and, due to the seasonal shifting of climatic belts, experiences warm-temperate conditions in winter and a tropical regime with occasional hurricanes in summer (Bosart and Schwartz, 1979).
No Name Pond is a hypersaline lake. Both the lake and the surrounding flats display prolific microbial mats whose morphology and consistency is clearly related to the water content (Fig. 3). The microbial mats are mainly built up by the 


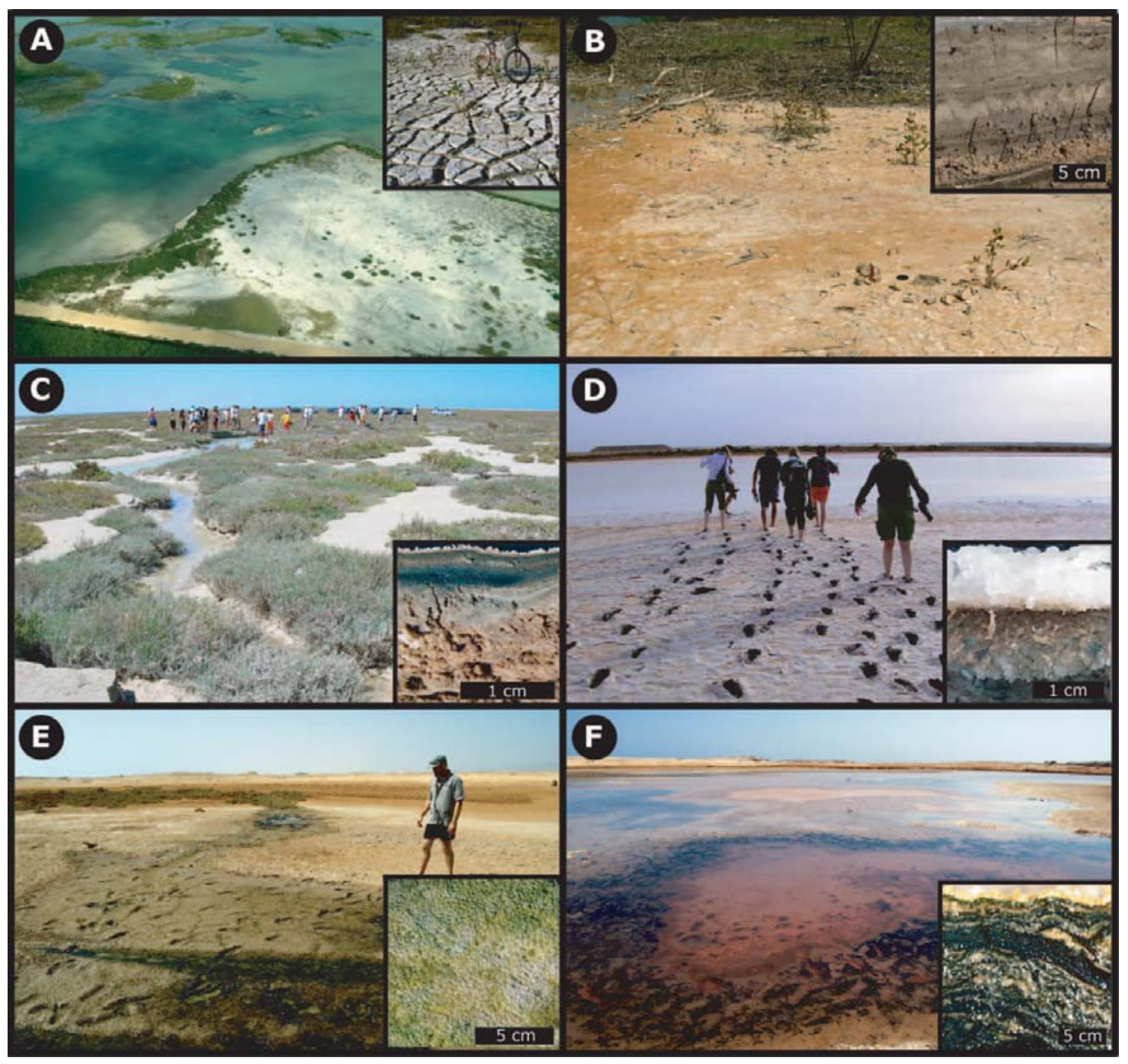

FIG. 2. Peritidal environments in Belize (A-B), Tunisia (C-D), and Egypt (E-F). (A) Aerial view of a supratidal flat about $2 \mathrm{~km}$ SW of San Pedro airport. The white color is due to the lithification (dolomitization) of microbial mats. Inset shows prism-cracked and completely dolomitized microbial mats; (B) Supratidal mangrove swamp at South Beach, about $2 \mathrm{~km} \mathrm{SW}$ of San Pedro. Inset shows a cross section of the thick microbial mat on top of a well-laminated peat; (C) Supratidal flats and marshes NW of Hassi Jerbi cut by small meandering tidal channels. Note the halophytic vegetation (Salicornia). Inset shows thick and rigid microbial mat on top of well-laminated, organic-rich sediment; (D) Sabkha Bou Jemel. Inset shows thick microbial mat, covered by a cm-thick crust of halite. While walking over the sabkha, one's feet sank deep into the underlying soft sediment forming deep tracks when the crust and mat were broken; otherwise, no tracks were left. Note the irregular and wide-gauge trackway of the person walking on the left, which is related to an unsure behavior; (E) Supratidal flats around Hypersaline Pond. Note the deep footprints in the water-saturated area at the bottom of the picture and the geologist who is unsure whether to pass or not. Inset shows gas bubbles on top of the microbial mat; (F) Hypersaline Pond. Note the trampled ground (human footprints) of the pond at the bottom of the picture. Inset shows a cross section of thick, gelatinous, and well-laminated microbial mat with halite crystals on the surface. (See Color Plate XXXV)

cyanobacterium Microcoleus sp. and the coccoid cyanobacteria Gloeocapsa sp. and Entophysalis sp. (Dupraz et al., 2004). From the shallower parts of the lake, Dupraz et al. (2004) described more or less continuous carbonate crusts, which form by early high-Mg calcite precipitation in the uppermost layer of the mats.

\section{Southern Tunisia}

In May 2005, we studied two areas: Sabkha Bou Jemel $\left(11^{\circ} 06^{\prime} 39^{\prime \prime} \mathrm{E}, 33^{\circ} 16^{\prime} 56^{\prime \prime} \mathrm{N}\right)$, located about $10 \mathrm{~km} \mathrm{~S}$ of Zarzis, and the Hassi Jerbi tidal flat $\left(10^{\circ} 59^{\prime} 60^{\prime \prime} \mathrm{E}, 33^{\circ} 38^{\prime} 38^{\prime \prime} \mathrm{N}\right)$ with its barrier-island system, connecting Jerba Island to the Tunisian coastline NW of the village of Hassi Jerbi (Fig. 1C). The climate in the wide coastal plain of southern Tunisia is subtropical semi-arid. Precipitation is irregular with episodic catastrophic floodings followed by long periods of drought, which may extend over several years (Medhioub and Perthuisot, 1981). Tides are in the microtidal range.

The barrier-island NW of Hassi Jerbi is mainly composed of bioclastic sands and surrounded by intertidal sand flats, supratidal flats, and marshes (Davaud and Septfontaine, 1995). 


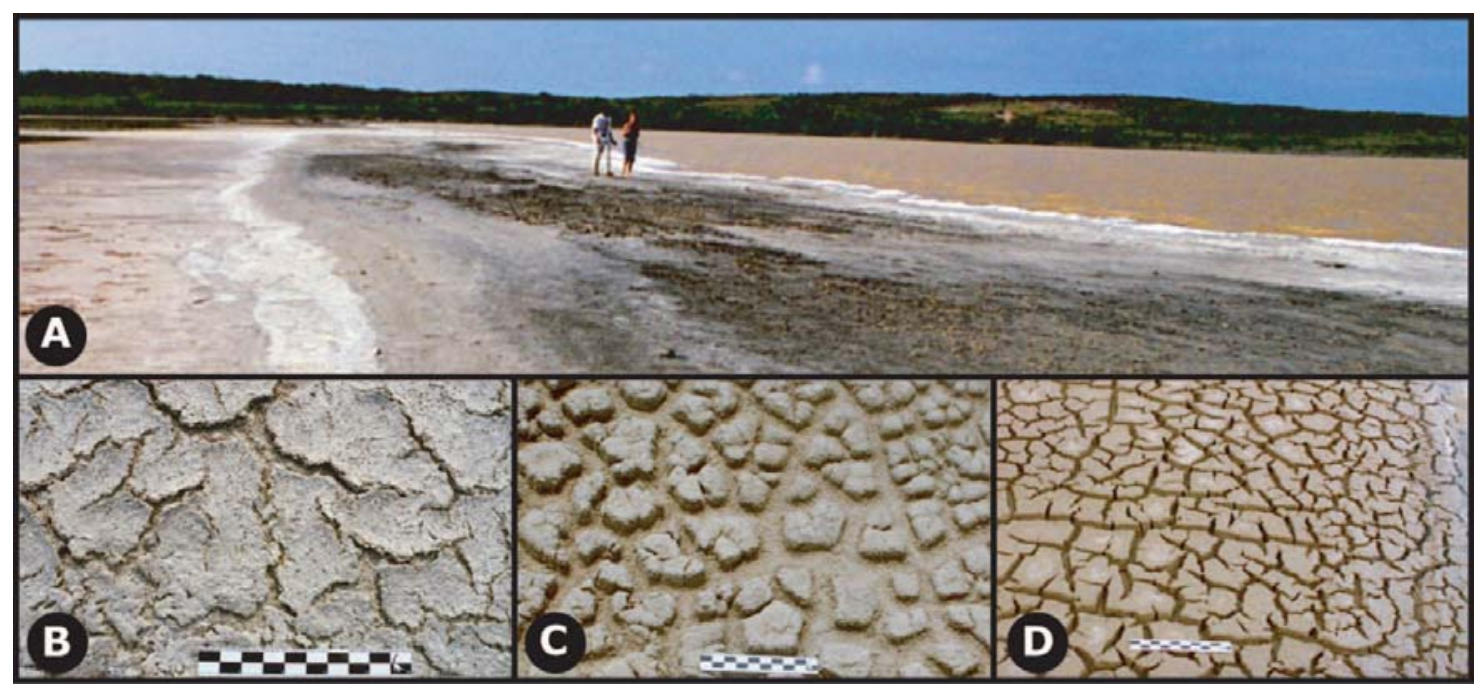

FIG. 3. (A) Typical zonation of microbial mats on the supratidal flats around No Name Pond (Eleuthera Island). View towards the N, geologists for scale. (B) Thin, brittle, and dry (crinkled and cracked surface with upcurled margins) mat on top of a consolidated cerithid packstone. When walking on this hard surface, the mat was slightly brecciated but no clear footprints were made. (C) Thick and moist mat with healed shrinkage cracks, exhibiting a cauliflower pattern and rounded edges, caused by the renewed growth of a mat within the cracks. Situated on top of a water-unsaturated cerithid packstone. This mat had such a high elasticity that even when deformed under the pressure of the foot, no footprints were registered after foot withdrawal. (D) Very thick and water-saturated smooth mat with very low yield strength on top of a water-unsaturated poorly-laminated cerithid packstone. The formation of cracks, which extend about $10 \mathrm{~cm}$ into the sediment, may be explained by different surface tensions between the thick mat and the underlying sediment (cerithid packstone). Here it was difficult to walk, as one's feet sank deep into the sediment and got stuck, forming deep tracks. Scale bars are $20 \mathrm{~cm}$. (See Color Plate XXXVI)

Footprints were studied in the intertidal and supratidal zones (Fig. 2C). On the lower intertidal sand flats, the microbial mats were just a thin film (biofilm) due to the grazing activity of cerithid gastropods (Fig. 5I), and footprints could easily be made. On higher intertidal flats to supratidal flats and marshes, on the other hand, the thick coherent mats were smooth to pustular, often multilaminated, and consolidated in a way that they could only be disintegrated by cutting with a knife, and superimposed on well-laminated sediment, rich in organic material (inset in Fig. 2C). Here, no fresh imprints could be made, but earlier footprints left during wet conditions could be studied. For more detailed descriptions of the microbial mats and microbially induced sedimentary structures, the reader is referred to Gerdes et al. (2000) and Noffke et al. (2001).

In addition, footprints were made in Sabkha Bou Jemel, which borders the restricted lagoon of Bahiret El Bibane (Fig. 1C). The lowest parts of the sabkha were filled with brine (Fig. 2D). On top of the water-saturated, peat-like and cerithid-bearing sediment, a thick, water-unsaturated microbial mat with a high yield strength was covered by a cm-thick crust of halite (inset in Fig. 2D).

\section{Southern Sinai (Egypt)}

In October 2006, footprints were studied in Egypt, in and on the flats surrounding the shallow Hypersaline Pond $\left(34^{\circ} 14^{\prime} 29^{\prime \prime} \mathrm{E}\right.$, $27^{\circ} 44^{\prime} 32^{\prime \prime} \mathrm{N}$ ), about $2 \mathrm{~km} \mathrm{NW}$ of Shark Observatory in Ras Muhammad National Park, on the southernmost tip of the Sinai peninsula (Fig. 1D). This area is located in the subtropical zone.
Receiving very little precipitation in any form, the climate is fully arid. The measured salinity of the pond was higher than $250 \%$ at the time of visit.

The area around the pond is desertic and xerophytic (Fig. 2E). The microbial mats of this pond are thick and gelatinous (inset in Fig. 2F). They appear to be similar to those of the well-studied Solar Lake, a small sea-margin pond located on the Gulf of Aqaba, $18 \mathrm{~km}$ south of Taba/Eilat, where the dominant cyanobacterium is Microcoleus chthonoplastes (e.g., Cohen, 1984; Krumbein et al., 1977).

\section{METHODOLOGY}

Human footprints in microbial mats were studied and documented in a wide range of present-day tidal-flat environments, which mainly differ from each other regarding the nature of the microbial mats (composition, thickness, water content, consistency) and the underlying sediment (composition, texture, water content). Only barefoot human footprints were analyzed because they are easily left at any place and time, even though other vertebrate footprints of birds, dogs, and lizards were also frequently encountered. Selected footprints or parts of them (e.g., displacement rims) were sampled. The microbial mats were characterized from a morphological point of view, applying commonly used terminology (e.g., Monty, 1972; Kendall and Skipwith, 1968; Davies, 1970; Logan et al., 1974; Hardie, 1977). In order to characterize the properties of the underlying sediment and to understand the evolution of the different environments during the Holocene, up to $1 \mathrm{~m}$-long sediment cores were taken 
by pushing or hammering a plastic tube into the unconsolidated sediment. Samples were solidified with epoxy, and thin-sections were made to characterize the sediment texture and facies.

\section{Terminology}

Deep track: True tracks made by a trackmaker sinking deeply into soft mud have been named deep tracks (Gatesy, 2003). In this case the foot penetrates through the sediment and the true track (the surface having been in direct contact with the foot) is located within the sediment and may reveal information about how the foot was placed (Gatesy et al., 1999; Gatesy, 2003).

Footprint (print, track): Used in a general way, without specifying the precise nature of the footprint (e.g., true track, undertrack, overtrack, etc.). Refers to a single footprint, not to a sequence of tracks or a trackway.

Footprint consolidation and lithification: The term consolidation is used to describe footprints, which are cohesive or hard and difficult to disintegrate. Lithification means that the sediment has been at least partially stabilized by early cementation (e.g., precipitation of carbonates).

Modified true track: This term is introduced in order to describe true tracks which have been modified by physicochemical and/or biological influences after they were made. They differ from true tracks in that they will not reveal fine details of the anatomy of the foot anymore, and from overtracks in that the tracked surface is not covered but disintegrated (Fig. 4B).

Overtrack: Appears in a horizon above the tracked surface. It forms by draping of the entire true track with sediment and/or by growth of a microbial mat and associated binding of sediment particles (Fig. 4C). An internal overtrack forms by draping of the true track sensu stricto inside the overall track only, by growth of a microbial mat and/or by trapping of sediment within the overall track (Fig. 4C). A rapid and important sedimentation event may also bury the overall track and the tracked surface without leaving behind an overtrack. In such a way, a homogeneous track fill (sediment fill) or natural cast of the overall track is formed (Fig. 4D).

Tracked surface (tracking surface): The tracked surface is the surface on which the animal (trackmaker) walks (Fornós et al., 2002), and which is exposed at the time of track formation. In a more proper sense the tracked surface is the sediment that has been in direct contact with the foot, and does not correspond to the initially exposed sediment surface in the case of underprints or deep tracks.

True track: Lockley (1991) called the track emplaced on the actual tracked surface true track. Walls around a true track are called track walls (Brown, 1999), and if these walls are not vertical, the track intersection with the tracked surface is larger than the dimensions of the trackmaker's foot and is

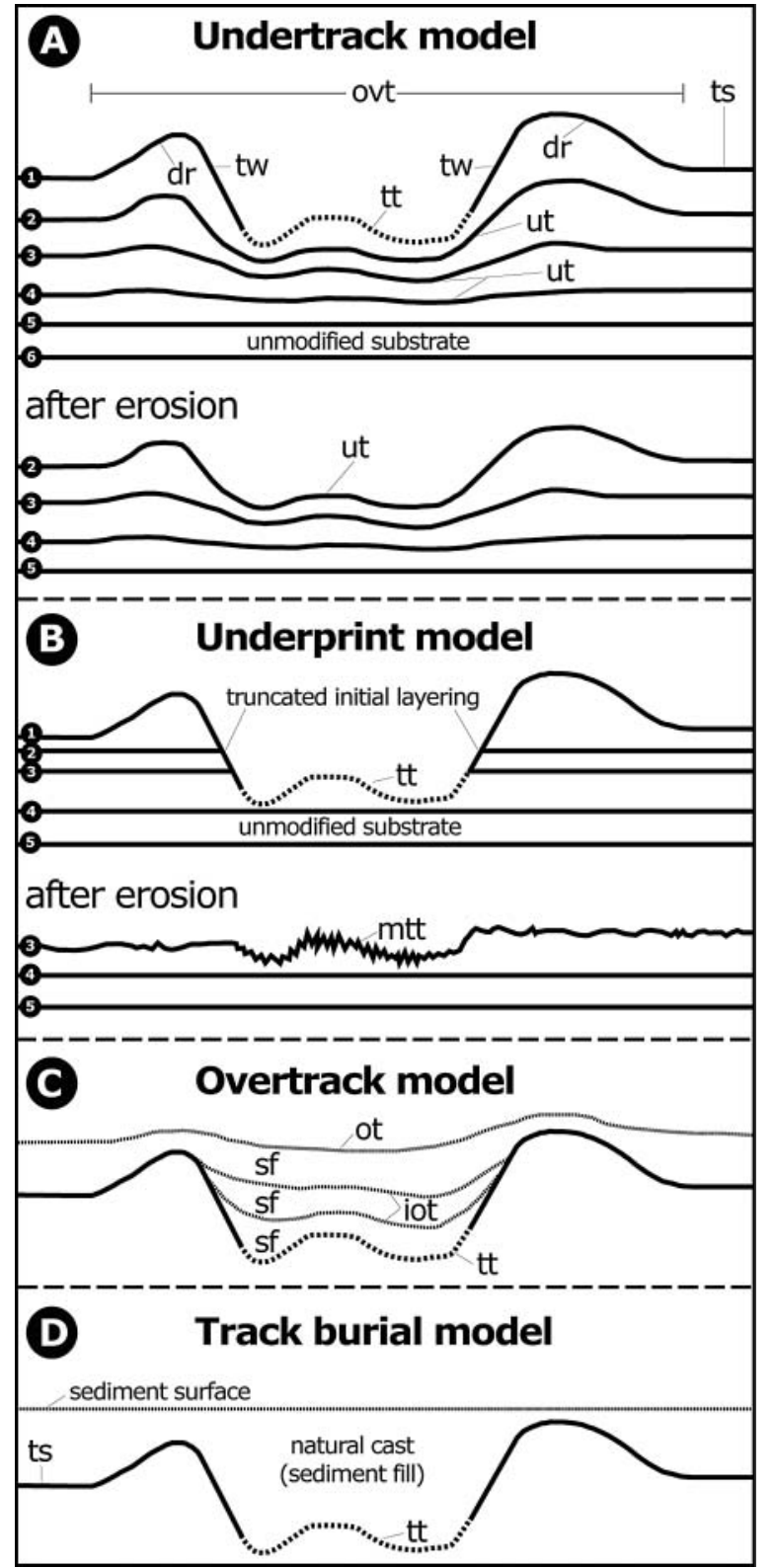

FIG. 4. Schematic longitudinal sections through a human footprint (following Allen, 1989, 1997), explaining the terminology used in the text: displacement rim (dr), overall track (ovt), sediment fill (sf), tracked surface (ts), track wall (tw), true track (tt), undertrack (ut). (A) Undertrack model showing the formation of undertracks through the compression of well-laminated sediment by pressure of the foot. (B) Underprint model, foot is breaking through the initial layering and the print is not left on the originally exposed sediment surface. When the sediment is split at a deeper layer the overall track is less complete. With ongoing erosion the overall track is less complete and the true track modified, leading to the formation of a modified true track (mtt). (C) Overtrack model showing a stack of internal overtracks (iot) and an overtrack (ot). (D) In the track burial model the track is filled up and buried by a rapid and important sedimentation event, forming a natural cast without an overtrack on top of the overall track. 
termed the overall track (Brown, 1999). Bulges, which may form around a true track, are called displacement rim (marginal ridge, raised rim, bourrelet) (Fig. 4A). Only the bottom of the track contains the direct impression of the trackmaker's foot. This is the true track sensu stricto, which may under appropriate substrate conditions and if the foot is placed in an ideal way reveal information about the anatomy of the trackmaker's foot. Such tracks were also named elite tracks, which have the connotation of well-preserved, visually-clear true tracks that are not distorted (e.g., Lockley and Hunt, 1995; Lockley and Meyer, 2000).

Underprint: Unlike undertracks, underprints are true tracks, which are produced when the foot breaks through several layers of sediment and leaves the true track on sediment below the initially exposed sediment surface. If in this case the sediment is split open at successively deeper layers, the overall track will be found to be less and less complete (Thulborn, 1990), whilst the true track sensu stricto may still reveal the anatomy of the foot. Only if an underprint is eroded, a modified true track will form (Fig. 4B).

Undertrack (transmitted or ghost print): a track that is formed in (bio)laminated and plastic substrate when the foot does not penetrate the sediment but compresses it in a way that it creates a miniature stratigraphic sequence or stack of transmitted prints (Thulborn, 1990; Lockley, 1991) (Fig. 4A). Consequently, after consolidation, the (laminated) sediment package may split at successively deeper bedding planes and reveal correspondingly shallower and less detailed versions of the track at different horizons.

\section{DESCRIPTION OF FOOTPRINTS}

The formation and morphology of footprints in microbial mats depend not only on the nature (composition, thickness, water content, degree of consolidation, etc.) of the mat itself but also on the characteristics (water content, grain size, lamination, degree of consolidation, presence of a lithified horizon) of the underlying sediment. Consequently, many different combinations are possible, which complicate a thorough description of the footprints. Nevertheless, it was found that the thickness of the microbial mat and the water content of the mat and of the underlying sediment are the most crucial factors for footprint morphology. The footprints in Figures 5, 6, and 7 were left by the first author ( $23 \mathrm{~cm}$ foot length, $70 \mathrm{~kg}$ weight). Figure 5 shows a series of footprints on thin and thick microbial mats with variable mat water content. Note that the limit between thin and thick mats was arbitrarily fixed at $3 \mathrm{~mm}$, that the water content is estimated and may be different in the underlying sediment, and that other substrate properties such as grain size or texture are not taken into account. Such a general approach is necessary because it is practically impossible to measure every variable in every footprint. Further footprints are illustrated in Figures 6 and 7.

\section{Dry Mats}

Poorly defined footprints were produced in thin and dry mats superimposed on dry but still soft (unconsolidated) sediment. In this case, the mat frequently cracked in such a way that the gross outline of the print was visible and extension of the crack pattern inside the print easily identified the shallow prints (Fig. 5A). Such prints may initiate further disintegration of the mat (e.g., overturning and reworking pieces by tidal flooding, wind, or surges) and the formation of mud chips or even flat-pebble conglomerates. Consequently, these footprints are fragile and have a very low preservation potential unless they are immediately buried after formation.

In thick and dry microbial mats, no footprints were formed if the mat had a very high elasticity (Fig. 3C), if the underlying sediment had a high yield strength, or was (partly) lithified. However, as thick microbial mats may form a continuous, strongly cohesive zone of low permeability, separating the underlying sediment from the atmosphere and protecting it against water loss, the sediment below a dry mat is not necessarily dry ("confined aquifer") (Porada et al., 2007). Thus, if the underlying sediment was still moist and soft, the dry mat sometimes broke at the border of the foot, and was pushed underneath the foot vertically into the underlying sediment. Such prints have a typical cracked surface, exhibit the gross outline of the foot, and are clearly deeper (Fig. 5B). In the case of a dry microbial mat superimposed on water-saturated sediment (mud), deep tracks formed if the mat broke in the center of the foot and was pushed to the sides of the print (Fig. 7). However, if in the same scenario the mat broke at the border of the foot and was pushed underneath the foot vertically into the underlying sediment, it acted as a sort of "snowshoe" (Fig. 7). Such footprints are a special case of true tracks since they exhibit the characteristics of a print left on a dry mat, but the initially exposed surface may be pushed relatively deep into the underlying sediment. Such prints may be easily preserved by simple filling up.

\section{Moist Mats}

In thin moist mats, the mats were compressed by the foot, and shallow but well-defined prints with anatomical details of the toes were formed, if the underlying sediment was of moderate yield strength and was not water unsaturated or water saturated (Fig. 5C). In thick moist mats, the footprints were shallow and less well defined (Fig. 5D, RP6 in Fig. 6A, and Fig. 6D). When a moist mat was overlying water-saturated sediment, deep tracks formed if the mat broke in the center of the print and was pushed to the sides of the print, forming vertical track walls.

\section{Water-unsaturated Mats}

Here, a great variability in footprint morphology was produced, including well-defined and poorly defined footprints. On thin and thick mats, well-defined footprints with anatomical details of the toes and well-defined displacement rims (with 


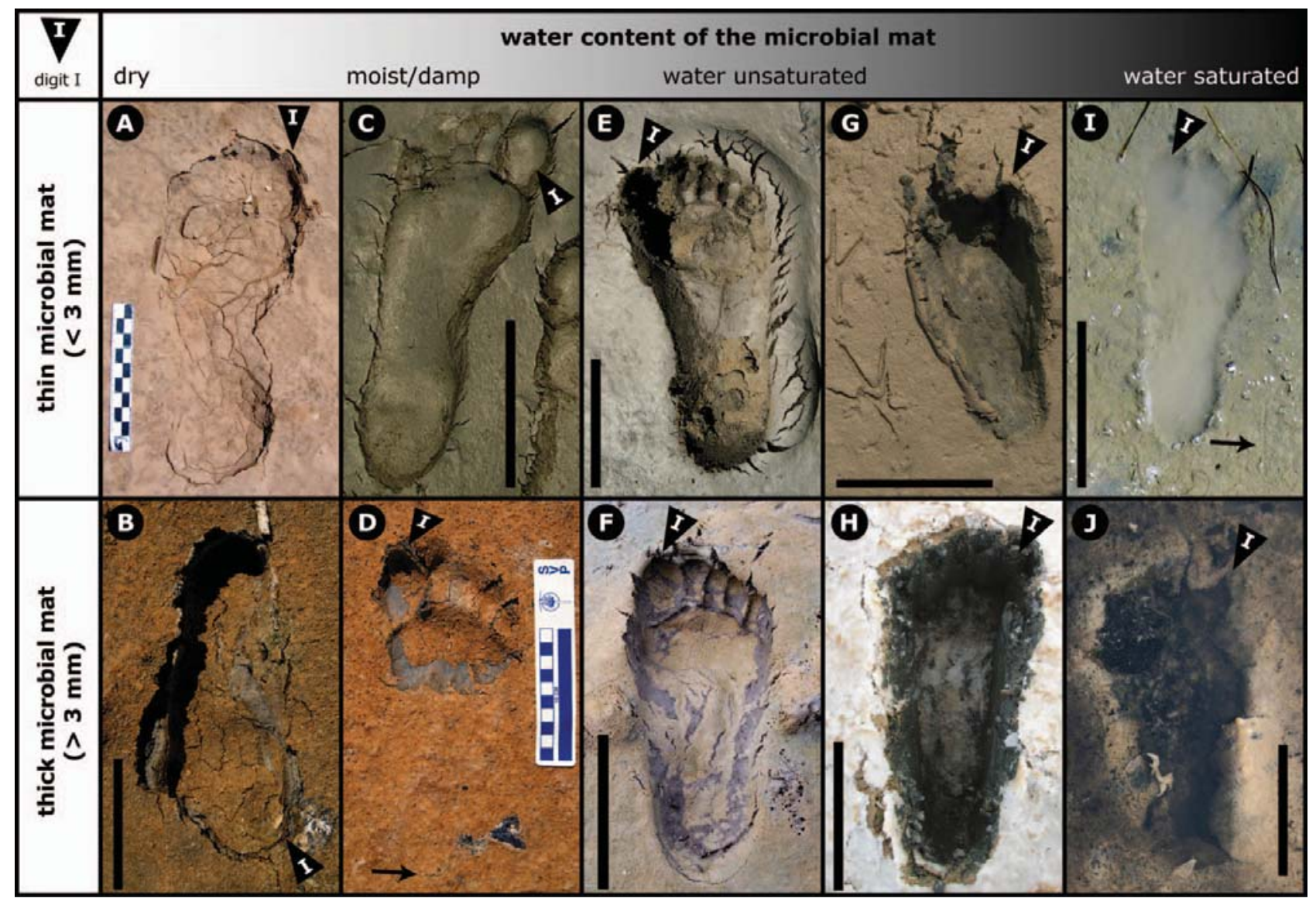

FIG. 5. Footprint morphology as a function of microbial mat thickness and water content of the mat and the underlying sediment. Arrows indicate the position of the big toe (digit I). All scale bars are $10 \mathrm{~cm}$. See text for description and interpretation. (A, H) Sabkha Bou Jemel (southern Tunisia); (B-G) Mangrove swamps near South Beach and supratidal flats and marshes SW of San Pedro airport (Ambergris Caye, Belize). Arrow in D points to the heel; (I) Intertidal sand flat NW of Hassi Jerbi (southern Tunisia), arrow points to grazing traces of cerithid gastropods, footprint is filled with water; (J) Hypersaline Pond (southern Sinai, Egypt). This footprint was covered by $10 \mathrm{~cm}$ of water. (See Color Plate XXXVII)

radial fractures in Fig. 5E) were formed if the underlying sediment still had relatively high yield strength. Thus, the mat was not penetrated but compressed and plastically deformed (Figs. 5E, 5F and LP5 to LP6 in Fig. 6A). Badly defined underprints exhibiting only the gross outline formed if the underlying sediment had a low yield strength or if it was water saturated (Figs. 5G and 5H). In Fig. 5G the foot penetrated through the mat into the underlying sediment. Figure 5G further demonstrates how track morphology also depends on trackmaker weight, as on the same surface shorebirds left wellpreserved tracks because their feet did not penetrate through the mat. In Figure $5 \mathrm{H}$ the foot formed a deep underprint, because it broke through a cm-thick layer of halite (inset in Fig. 2D) and the underlying water-unsaturated microbial mat and pushed them to the sides of the print, forming vertical track walls.

\section{Water-Saturated Mats}

In water-saturated mats, only poorly defined footprints were made. In both thin and thick mats, footprint morphology mainly depended on the nature of the underlying sediment, as the foot easily penetrated through the gelatinous mats. If the underlying sediment was water-saturated but not very thick (Fig. 5I), or if it was consolidated (Fig. 6B), the prints display the gross outline of the foot. Figure 5J shows a footprint that was formed in a water-saturated, gelatinous mat on top of a water-saturated and thick layer of peat. In this case, the foot penetrated deep into the sediment and a deep track formed. The print LP1 in Figure 6B was left in a thixotropic microbial mat on top of a lithified sediment layer. It does barely exhibit the gross outline of the foot, as it collapsed after foot withdrawal. This track is best described as an underprint with extramorphological collapse features.

\section{Consolidated Footprints}

Consolidated and/or (partially) lithified microbial mats preserved footprints were left while the mats were still moist and plastic. It is unknown when and under what circumstances 


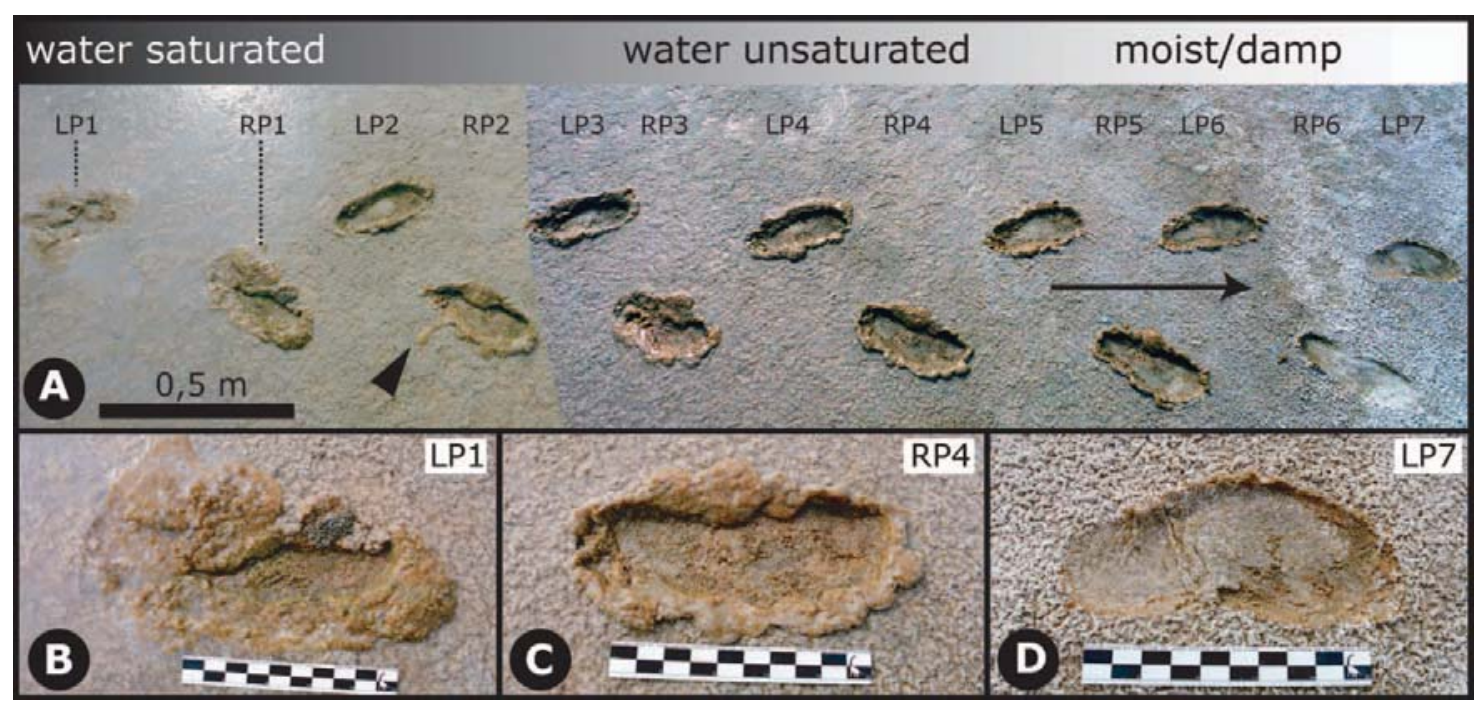

FIG. 6. (A) Changing footprint morphology along a trackway left at the border of No Name Pond (Eleuthera Island, Bahamas). Here a lithified layer was covered with a 3-5 cm thick microbial mat with variable water content. LP stands for left pes, RP for right pes. Arrow on RP2 points to expelled sediment. The color differences are due to a splicing of two photographs; (B) Partially collapsed footprint (true track with extramorphological features) showing only the gross outline; (C) Footprint with displacement rim and sediment collapse feature into the area of the foot's longitudinal arch; (D) Shallow footprint without displacement rim. Scale bars in B, C, and D are $20 \mathrm{~cm}$. (See Color Plate XXXVIII)

(e.g., water content of the mat) the solidified footprints in Figures 8 and 9 were made.

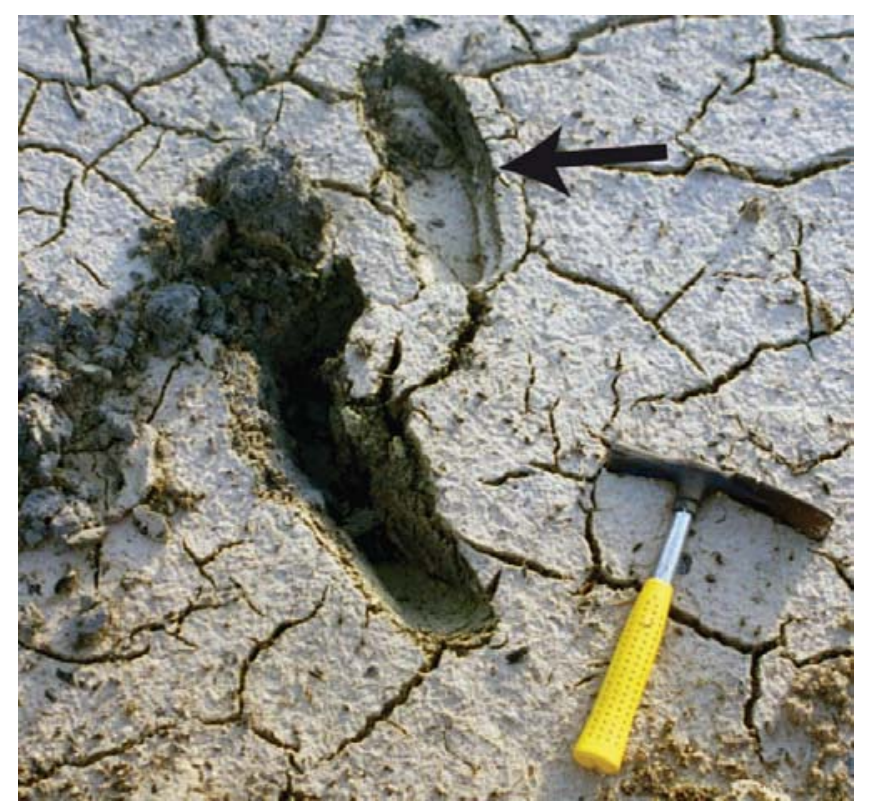

FIG. 7. Thick and almost dry (initial formation of desiccation cracks), smooth mat on top of a thick layer of water-saturated carbonate mud. In the footprint in the center of the picture, the microbial mat broke in the central part of the print and was pushed to the sides of the print. Consequently, the foot sank over $40 \mathrm{~cm}$ deep into the sediment and formed a deep track. In the other print (arrow) the microbial mat broke at the border of the foot, and was pushed underneath the foot vertically into the sediment. Hammer for scale, No Name Pond (Eleuthera Island, Bahamas). (See Color Plate XXXIX)
Figure 8 shows several footprints, which were found in close proximity to each other on the supratidal flats and marshes NW of Hassi Jerbi (Tunisia). Even if they are not part of a trackway, it is suggested that they were left more or less at the same time, while the microbial mat was still moist and active, after a rainy period or after an exceptionally high (storm) tide. Once the footprints were made, the mats kept growing as long as they remained moist. This growth modified the original morphology to different degrees and led to the formation of internal overtracks (Fig. 8B) and overtracks (Fig. 8D). Later, the mats dried up and consolidated or lithified.

Other consolidated footprints are shown in Figure 9. All such footprints could be incorporated into the sedimentary record. Some exhibit nothing more than the gross outline of the pes and would be difficult to identify as footprints of hominids. Figure 9A shows a footprint of a child with impressions of the toes. As this print has clearly started to suffer some alteration, it can be described as a consolidated modified true track. This print was left in a $\mathrm{cm}$-thick microbial mat and was originally probably similar to the ones shown in Figures 5E and 5F. Figures 9B and 9C show footprints, which were left in a thick microbial mat and which may initially have been as well defined as the footprints in Figures 5E and 5F. The print in Figure 9B was consolidated and then covered by about $10 \mathrm{~cm}$ of water. The one in Figure 9C was highly modified by the ongoing growth of the microbial mat and by precipitation of halite, which led to the formation of a poorly defined overtrack. Finally, the footprint in Figure 9D was probably left in a moist microbial mat similar to the ones in Figures 5C and 5D. Prior to consolidation, this print suffered from the growth of the microbial mat, which blurred its original morphology and led to the formation of an overtrack. 


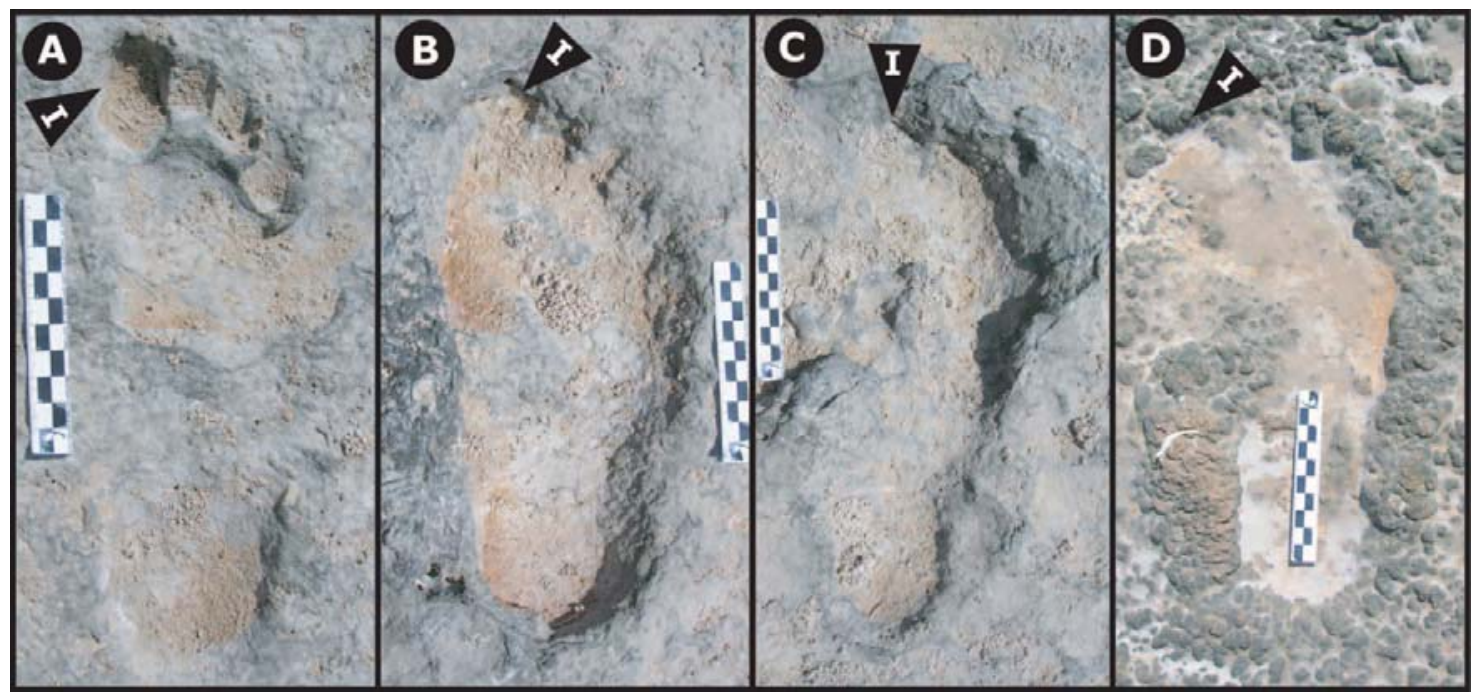

FIG. 8. Modification of footprint morphology by consolidation and/or continued growth of the microbial mat. All footprints are right pes prints of unknown individuals and the arrows indicate the position of the big toe (digit I). The microbial mats were dry, inactive, and consolidated in such a way that no further footprints could be made at the time the pictures were taken. All pictures are from the supratidal flats NW of Hassi Jerbi (southern Tunisia), scale bars are $10 \mathrm{~cm}$. (A) Well-defined footprint exhibiting anatomical details of the toes and heel; (B) Footprint with a stack of internal overtracks. General outline is still well defined and the position of the digits can be recognized; (C) Outline starts to disintegrate but the position of digits I and II can still be identified. Note increased growth of microbial mat on topographic highs (displacement rims on the upper right of the print); (D) Blurring of the footprint by growth of a pustular microbial mat. The gross outline can still be recognized but the approximate position of digit I can only be estimated. This is a good example of the formation of an overtrack by the growth of a microbial mat. (See Color Plate XL)

\section{DISCUSSION}

This study of hominid footprints in microbial mats of present-day tidal-flat environments reveals a great variability in footprint morphology. Even on an ideal substrate (moist to water-unsaturated, plastic microbial mat) it was difficult to deliberately register a perfect footprint with anatomical details such as the toe impressions, which could unequivocally be identified as an unmodified true track. A perfect footprint

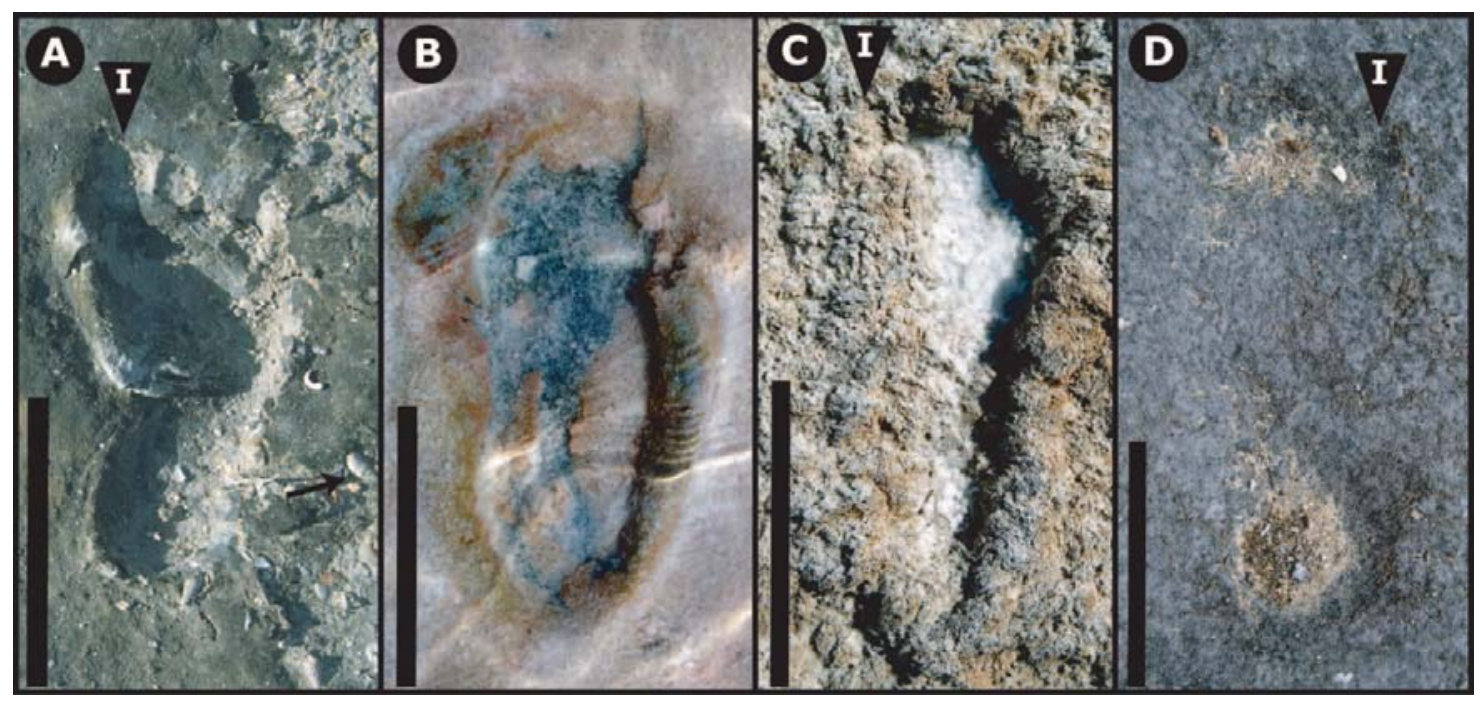

FIG. 9. Modification of footprint morphology by continued growth and/or consolidation of the microbial mat. Where possible, the position of digit I is indicated. Scale bars are $10 \mathrm{~cm}$. (A) Supratidal flat SW of San Pedro airport (Ambergris Caye, Belize). Modified true track. Note the presence of (dead) cerithid gastropods (arrow), the well-defined displacement rim at the inner (left) margin of the (right) print and the torn away mat in the upper right; (B) Hypersaline Pond (southern Sinai, Egypt). Overtrack or modified true track with well-defined displacement rim on the right side of the print; (C) Supratidal flat around Hypersaline Pond (southern Sinai, Egypt). Continued growth of the microbial mat and precipitation of halite led to a poorly-defined overtrack; (D) Supratidal flat SW of San Pedro airport (Ambergris Caye, Belize). Very shallow and barely visible overtrack. (See Color Plate XLI) 
is even more unlikely to occur if the trackmaker produces different footprint morphologies due to changing behavior (walking, running, jumping) (e.g., Thulborn and Wade, 1989; Milàn, 2006). In addition, footprint morphology is related to the properties (namely consistency) of the substrate being traversed (e.g., Farlow, 1992; Marty et al., 2006; Uchman and Pervesler, 2006), and poor footprint registration can just be due to unsuitable substrate properties (e.g., Brand, 1996; Diedrich, 2002). Identification of true tracks is further complicated in the fossil record where footprints undergo different stages of taphonomy and are at different stages within the diagenetic sequence of development. This corroborates Allen (1997) who stated that only a very small proportion of the tracks in a given area are capable of yielding diagnostic taxonomic information about the animals that made them, and McKeever and Haubold (1996) who showed that many Permian ichnogenera are nothing more than substrate or behavioral variants of the same trackmaker.

\section{Factors Controlling Footprint Morphology}

Footprint morphology is controlled and affected by substrate properties such as consistency, sediment composition, grain size, texture, yield strength, water content, rate of consolidation, and the presence and nature of microbial mats. Allen (1997) and Manning (2004) suggested that the water content and the yield strength of the sediment at the time of track formation are crucial and most strongly control track morphology. Scrivner and Bottjer (1986) and Allen (1997) classified footprint morphologies as a function of water (moisture) content and yield strength of the sediment (mud). Their classification can be summarized as pertaining to (a) dry and hard, stiff to firm mud; (b) moist or slightly damp stiff mud; (c) water-unsaturated soft mud; and (d) water-saturated semi-liquid mud.

In the present work, this classification proved very helpful for the gross characterization of microbial mats and the underlying sediment, even if the boundaries between these four categories are inherently gradational (see Fig. 6). Other factors were found to be of importance as well. First, the yield strength of a mat depends on its thickness and elastic limit. Furthermore, the consistency of the underlying sediment, presence or absence of a lithified layer below the microbial mat, and the position of the water table are also important for the formation and the morphology of a footprint. Consequently, different combinations of the properties of the microbial mat and the underlying sediment result in a broad range of morphologies for footprints (true tracks, underprints, and deep tracks) left by a single trackmaker. The formation of undertracks is only possible in well-laminated and plastic moist to water-unsaturated sediment.

On dry and consolidated mats overlying dry unconsolidated sediment, a footprint only forms if the trackmaker exerts enough pressure to crack the mat, which is only possible if the mat is very thin or the trackmaker very heavy. Dry and consolidated mats with a thickness of $3 \mathrm{~mm}$ or more were often found to be either very elastic or, if already consolidated, very rigid and thus difficult to deform permanently. In the presence of a high water table it has been observed, that dry and firm microbial mats were often superimposed on unlaminated and water-unsaturated to water-saturated sediment. In this scenario, the mat frequently broke around the foot and was pushed underneath the foot vertically into the sediment. This led to the formation of particular true tracks, because the footprint was left on the originally exposed microbial mat, which was pushed relatively deep into the underlying sediment. When the mat broke in the central part of the foot and was pushed to the sides of the print, a deep track or an underprint was formed. If in the latter case the mat is still slightly plastic, this could explain the formation and preservation of lateral, vertical scratch marks as sometimes observed on deep dinosaur footprints (e.g., Diffley and Ekdale, 2002; Milàn et al., 2005; Platt and Hasiotis, 2006).

The morphologically best-defined prints are produced in moist to water-unsaturated, very plastic and thick microbial mats on top of sediment with high yield strength. In water-saturated microbial mats, generally only poorly defined footprints are left, even if sometimes reasonably well-defined prints form if a water-saturated mat is superimposed on a lithified layer. The formation of well-defined displacement rims (as frequently observed around the prints of large dinosaurs) occurs in thick, plastic, moist to water-unsaturated microbial mats on top of moist to water-unsaturated sediment. Our observations show that shallow prints left in moist to water-unsaturated microbial mats have the best-defined morphology and can be used for ichnotaxonomical purposes. Those left in dry or water-saturated mats are generally poorly defined, but they can be used for the reconstruction of the paleoenvironment.

\section{Footprint Taphonomy}

Preservation of animal footprints in the fossil record is strongly dependent on taphonomic processes, which occur after registration of the footprint (track survivorship curves of Cohen et al., 1991). Generally, exposed tracks degrade rapidly after formation and have a low preservation potential. The amount of time between footprint formation and burial affects their preservation potential (Laporte and Behrensmeyer, 1980), as well as the degree of time-averaging of the ichnoassemblage (Cohen et al., 1993).

Many taphonomical factors affect a footprint after its formation. Destructive processes include vertebrate trampling, insect and other invertebrate bioturbation, root growth, weathering processes (heavy rainfall, wind deflation, desiccation with associated cracking and fracturing), deformation through displacive growth of evaporites, flooding and subsequent wave and seiche reworking or fluctuations of the groundwater table (e.g., Tucker and Burchette, 1977; Laporte and Behrensmeyer, 1980; Cohen et al., 1991; Demathieu, 1991; Nadon, 2001; Scott et al., 2007). These processes hinder footprint preservation or at least modify or obliterate the original true track, leaving behind 


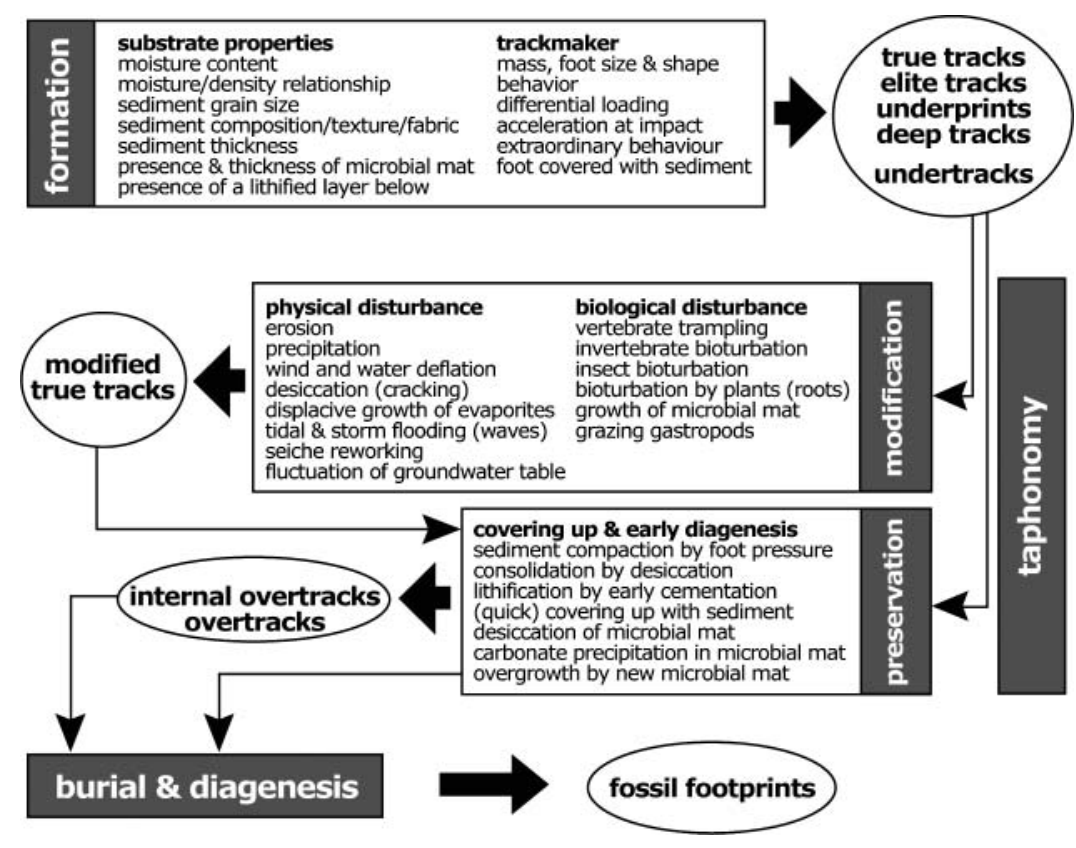

FIG. 10. Processes acting during footprint formation and taphonomy. Note that erosion is possible during different time frames, and even the fossil footprint itself may be subjected to erosion prior to discovery.

a modified true track. Taphonomic processes that potentially preserve footprints are early cementation (of the sediment or within the microbial mat), rapid covering by sediment, and overgrowth by microbial mats (Fig. 10).

This study shows that microbial mats may enhance footprint preservation by binding and stabilizing the sediment in which the trace was made, by overgrowth, by consolidation through drying, and also by lithification (carbonate precipitation within the microbial mat and early-diagenetic cementation). Nonetheless, to preserve a perfectly defined true track, the microbial mat must die and consolidate shortly after footprint formation, and the tracked surface must be covered by sediment prior to the development of a new microbial community. Ongoing growth of the mat after footprint formation consolidates the print but will also cover and obliterate its original morphology, producing an overtrack. It has been observed that growing microbial mats may thicken on top of positive reliefs such as the displacement rims. However, if humidity remains only within a deep footprint, the microbial mat continues to grow within the footprint but not around it, thus slowly filling it up and forming a stack of internal overtracks. Finally, mat growth also depends on other extrinsic factors such as sedimentation rate, light, salinity, and temperature (e.g., Dupraz et al., 2006).

Based on computational models, Henderson (2006) suggested that a weathered (tridactyl) true track cannot be confused with a freshly exposed (simulated) undertrack. Nonetheless, depending on the degree of modification, our study implies that true tracks are difficult to identify unambiguously because they may also look similar to overtracks. Furthermore, accretion and erosion may occur on many time scales and a track can repeatedly be partly filled by sediment, or partly or wholly emptied (Allen, 1997). In the case of an underprint, its upper part may be modified by erosion before final burial.

\section{Footprint Consolidation}

The rapid consolidation of a footprint is crucial to prevent obliteration and deformation prior to and/or during subsequent burial (Phillips et al., 2007). Our observations show that consolidated or partly lithified footprints are commonly found in the higher intertidal zone and especially on supratidal flats and marshes. These footprints show a broad range of preservation states due to differences in substrate consistency at the time of their formation, different degrees of overgrowth by microbial mats, and the different nature and morphology of microbial mats.

On the supratidal flats SW of San Pedro airport (Ambergris Caye, Belize) we found that completely lithified (dolomitized), mud-cracked biolaminites make up the upper 20 to $30 \mathrm{~cm}$ of the sediment (inset in Fig. 2A). Widespread dolomitization of peritidal flats on Ambergris Caye was already described by Mazzullo et al. (1987) and Gregg et al. (1992). Mazzullo et al. (1987) stated that these "massive beds of dolomite are characterized by a marked subtidal appearance, as they lack typical supratidal features." This is in contrast to our own observations because we found pronounced desiccation (prism) cracks (inset in Fig. 2A) and tetrapod footprints in the dolomitized microbial mats. We also observed consolidation and (partial) lithification of microbial mats in the other study areas and we suggest that this is one of the major processes of footprint preservation in tidal-flat environments. 


\section{Footprints and Environment}

In microbial mats, footprints are generally only produced during wet conditions. During periods of drought, the mats consolidate rapidly, getting hard and rigid and making it almost impossible even for a heavy trackmaker to leave a footprint. Moreover, such consolidated microbial mats are difficult to disintegrate and even resist heavy rainfall. New footprints can only be made once a new microbial community is in place after renewed wetting. This narrows the time-frame during which footprints are registered and diminishes the time-averaging of an ichnoassemblage.

Ginsburg et al. (1977) introduced an exposure index for tidalflat environments, which links characteristic sedimentary and organic features to the hydroperiod, that is, to the time duration during which the ground surface at a given site is covered with water. In environments located far away from the coastline, the exposure index is higher and the hydroperiod shorter, as wetting only occurs sporadically during very high tides (spring tides, equinoxial tides, storm tides) or during the rainy season. On a surface with an exposure index higher than $90 \%$, footprints can only be formed during the wet season or after a major storm. Consequently, if a large set of footprints is available, the general preservation state of footprints of trackmakers frequently traversing a tidal flat may yield additional important information about the exposure index of the different tidal-flat environments (Marty, 2008).

\section{Incorporation of Footprints into the Sedimentary Record}

It is the sedimentation regime that finally determines if preservation will take place and if a footprint will be incorporated into the sedimentary record. The probability of footprint preservation is minimal during long-lasting periods of exposure without any sedimentation, and preservation is favored by rapid and significant preservation events. Consequently, footprints are most commonly preserved in environments that experience periodic or cyclic accumulation of sediment (Thulborn, 1990), as typically observed on tidal flats.

While the upper intertidal zone is flooded at every high tide, flooding of supratidal flats and marshes only occurs during exceptionally high tides and with storms, resulting in a sudden influx of sediment-laden water even far inland from the coastal zone (e.g., Roehl, 1967; Monty, 1972; Hardie, 1977; Boss and Neumann, 1993; Rankey et al., 2004; Bourrouilh-Le Jan, 2007). Important sediment influx covers up footprint-bearing surfaces. On top of these sediment layers, new microbial mats may grow and protect them from disintegration (Ginsburg and Hardie, 1975; Hardie and Ginsburg, 1977). Simultaneously, new footprints may form in these mats as long as they remain moist. Thus, repeated tide and/or storm sedimentation explains the preservation of superimposed footprint-bearing surfaces in biolaminites. On a larger time-scale, the preservation potential of tidal-flat sediments is best during transgression, when new accommodation space is created (e.g., Lockley et al., 1992).
During relative sea-level or lake-level falls on the other hand, the enhanced erosional potential will most likely destroy the track-bearing surfaces.

\section{Implications for the Study of Fossil Footprints}

The problem of the distinction between true tracks and undertracks has long been recognized in vertebrate ichnology (Hitchcock, 1858). This distinction is important because only true tracks can give useful information relevant to ichnotaxonomic and paleoecological studies. This problem is further complicated by the presence of true tracks with extramorphological features, modified true tracks, internal overtracks, and overtracks. Nadon (2001) and Milàn and Bromley (2006) suggested that undertracks are always less detailed than true tracks. However, in the case of a strongly modified true track, the undertrack may exceptionally reveal more information about the trackmaker (Milàn et al., 2004) or its behavior (Avanzini, 1998; Gatesy et al., 1999). Our study shows that consolidated overtracks and stacks of internal overtracks are frequently encountered in modern tidal-flat environments. It is often difficult to distinguish such tracks from true tracks, because consolidated, unmodified true tracks with anatomical details are only seldom found. We suggest that modified true tracks and overtracks are commonly incorporated into the sedimentary record and probably make up an important part of the fossil footprint record, and that unmodified true tracks, which can easily be identified as true tracks because of the presence of anatomical details, are the exception in the fossil record. The simple fact that even the least modified true track in the fossil record is lithified means some modification has occurred through the processes of lithification and diagenesis. Moreover, in fossil biolaminites, the rock does not necessarily split at the original tracked surface and thus, in the outcrop, we may often observe undertracks or overtracks. Undertracks are relatively easily incorporated into the sedimentary record because they are already within the sediment at the time of formation, while the original true track may be eroded prior to burial (Lockley, 1991). However, they only form under very particular conditions and may thus be not as common as previously thought.

\section{CONCLUSIONS AND PERSPECTIVES}

- In recent microbial mat-covered tidal-flat environments in differing tropical and subtropical climatic settings, a wide range of morphologies of human footprints was formed. This variability depends on the water content, thickness and nature of the microbial mat and the underlying sediment. Nature, thickness and water content of the mat are crucial for its yield strength, plasticity, and its elastic limit. If the mat is broken or penetrated by the pressure of the foot, the nature and water content of the underlying sediment becomes the determining factor for footprint 
morphology, and either an underprint or a deep track is produced.

- Microbial mats are a significant factor for footprint preservation in modern tidal-flat environments. Once a footprint is left, it may be consolidated by simple desiccation of the microbial mat or by lithification due to carbonate precipitation within the mat. It may also be preserved by ongoing growth of the mat. However, continued microbial growth may seriously affect the initial footprint morphology and lead to the formation of a stack of internal overtracks or of an overtrack.

- Amongst consolidated or lithified footprints, unmodified true tracks with anatomical details have only occasionally been found. Poorly-defined true tracks, modified true tracks, internal overtracks, and overtracks were most frequently observed. In the fossil record such footprints make ichnotaxonomy difficult but may be a valuable tool for paleoenvironmental and paleoecological reconstructions, when combined with sedimentological evidence.

- We assume that the incorporation of an unmodified true track with anatomical details into the sedimentary record necessitates very particular conditions. Modified true tracks and overtracks are relatively easy incorporated into the sedimentary record and they may make up an important part of the fossil footprint record. They may even be more common than undertracks, because the latter only form under particular sediment conditions.

- In fossil biolaminites the sediment often does not split at the original tracked surface and thus underor overtracks are commonly exhibited in outcrop.

- In the fossil record, the unambiguous distinction between poorly defined true tracks, modified true tracks, undertracks, internal overtracks, and overtracks will remain a difficult task. True tracks may only be identified as such if they exhibit sufficient anatomical details, or if further evidence is gathered by detailed sedimentological studies of the footprint-bearing surface and the under- and overlaying layers. This underlines the importance of a systematic, three-dimensional study of footprints together with sedimentological analyses.

- So far, our conclusions are based on empirical observations from several tidal-flat environments. Further research should focus on long-term surveys of footprints in living and dead microbial mats of known biological composition in suitable tidal-flat environments.

\section{ACKNOWLEDGEMENTS}

We gratefully acknowledge the Swiss National Science Foundation (grant 20-109214.05) for the funding of the $\mathrm{PhD}$ of D. M. and the financing of the Belize field trip, and the
CUSO (Conférence universitaire de Suisse occidentale) for the partial financing of the field trips to Eleuthera (Bahamas) and southern Sinai (Egypt). The Nature Conservation Management and Training Center (Sharm El Sheikh) of the Egyptian Environmental Affairs Agency is thanked for access and guiding in the Ras Muhammad National Park, and C. Neururer (University of Fribourg) for salinity measurements in Hypersaline Pond. Reviews by M. G. Lockley and H. A. Curran improved the manuscript. S. G. Pemberton and M. G. Lockley are thanked for editorial work and for accepting us to contribute to this special volume on hominid footprints.

\section{REFERENCES}

Allen, J. R. L. 1989. Fossil vertebrate tracks and indenter mechanics. Journal of the Geological Society of London, 146:600-602.

Allen, J. R. L. 1997. Subfossil mammalian tracks (Flandrian) in the Severn Estuary, S. W. Britain: mechanics of formation, preservation and distribution. Philosophical Transactions of the Royal Society of London, serie B, 352:481-518.

Avanzini, M. 1998. Anatomy of a footprint: Bioturbation as a key to understanding dinosaur walk dynamics. Ichnos, 6:129-139.

Bauld, J. 1984. Microbial mats in marginal marine environments: Shark Bay, Western Australia, and Spencer Gulf, South Australia. In Cohen, Y., Castenholz, R. W. and Halvorson, H. O. (eds.), Microbial mats: Stromatolites. MBL lectures in biology 3. Alan R. Liss, New York, p. 39-58.

Bosart, L. F. and Schwartz, B. E. 1979. Autumnal rainfall climatology of the Bahamas. Monthly Weather Review, 107:1663-1672.

Boss, S. K. and Neumann, A. C. 1993. Impacts of Hurricane Andrew on carbonate platform environments, northern Great Bahama Bank. Geology, 21:897-900.

Bourrouilh-Le Jan, F. G. 2007. Very high sedimentation (supratidal hurricane deposits) and mid-Holocene highstand on carbonate platforms, Andros, Bahamas: An alternative view. Sedimentary Geology, 199:29-49.

Brand, L. R. 1996. Variations in salamander trackways resulting from substrate differences. Journal of Paleontology, 70:1004-1010.

Brehm, U., Gasiewicz, A., Gerdes, G., and Krumbein, W. E. 2002. Biolaminoid facies in a peritidal sabkha: Permian platy dolomite of northern Poland. International Journal of Earth Sciences, 91:260-271.

Brown, T. Jr. 1999. The science and art of tracking-nature's path to spiritual discovery. Berkley Books, New York, 219 p.

Burne, R. V. and Moore, L. S. 1987. Microbialites: Organosedimentary deposits of benthic microbial communities. Palaios, 2:241-254.

Chafetz, H. S. and Buczynski, C. 1992. Bacterially induced lithification of microbial mats. Palaios, 7:277-293.

Cohen, A., Halfpenny, J., Lockley, M. G., and Michel, E. 1993. Modern vertebrate tracks from Lake Manyara, Tanzania and their paleobiological implications. Paleobiology, 19:443-458.

Cohen, A., Lockley, M. G., Halfpenny, J., and Michel, E. 1991. Modern vertebrate track taphonomy at Lake Manyara, Tanzania. Palaios, 6:371-389.

Cohen, Y. 1984. The Solar Lake cyanobacterial mats: Strategies of photosynthetic life under sulphide. In Cohen, Y., Castenholz, R. W. and Halvorson, H.O. (eds.), Microbial mats: Stromatolites. MBL lectures in biology 3. Alan R. Liss, New York, p. 133-148.

Cohen, Y., Castenholz, R. W., and Halvorson, H. O. (eds.). 1984. Microbial mats: Stromatolites. MBL lectures in biology 3. Alan R. Liss, New York, 498p.

Conti, M. A., Morsilli, M., Nicosia, U., Sacchi, E., Savino, V., Wagensommer, A., Di Maggio, L., and Gianolla, P. 2005. Jurassic dinosaur footprints from southern Italy: Footprints as indicators of constraints in paleogeographic interpretation. Palaios, 20:534-550. 
Davaud, E. and Septfontaine, M. 1995. Post-mortem onshore transportation of epiphytic foraminifera: Recent example from the Tunisian coastline. Journal of Sedimentary Research, 65:136-142.

Davies, G. R. 1970. Algal-laminated sediments, Gladstone Embayment, Shark Bay, Western Australia, In Logan, B. W., Davies, G. R., Read, J. F. and Cebulski, D. E. (eds.), Carbonate sedimentation and environments, Shark Bay, Western Australia, AAPG (American Association of Petroleum Geologists) Memoir, 13: 169-205.

Davis, R. B., Minter, N. J., and Braddy, S. J. 2007. The neoichnology of terrestrial arthropods. Palaeogeography, Palaeoclimatology, Palaeoecology, 255:284-307.

Demathieu, G. R. 1991. Prevalent Lebensspuren on beaches of the Mediterranean coast of Languedoc, France, and the influence of the winds on their preservation. AAPG (American Association of Petroleum Geologists) Bulletin, 75: p. 559.

Demicco, R. V. and Hardie, L. A. 1994. Sedimentary structures and early diagenetic features of shallow marine carbonate deposits. SEPM (Society for Sedimentary Geology) Atlas Series, 1:265p.

Diedrich, C. 2002. Vertebrate track bed stratigraphy at new megatrack site in the Upper Wellenkalk Member and orbicularis member (Muschelkalk, Middle Triassic) in carbonate tidal flat environments of the western Germanic Basin. Palaeogeography, Palaeoclimatology, Palaeoecology, 183:185-208.

Diedrich, C. 2005. Actuopalaeontological trackway experiments with Iguana on intertidal flat carbonates of the Arabian Gulf-a comparison to fossil Rhynchosauroides tracks of Triassic carbonate tidal flat megatracksites in the European Germanic Basin. Senckenbergiana maritima, 35:203-220.

Diffley, R. L. and Ekdale, A. A. 2002. Footprints of Utah's last dinosaurs: Track beds in the Upper Cretaceous (Maastrichtian) North Horn Formation of the Wasatch Plateau, Central Utah. Palaios, 17:327-346.

Dupraz, C. and Visscher, P. T. 2005. Microbial lithification in marine stromatolites and hypersaline mats. Trends in Microbiology, 13:429-438.

Dupraz, C., Pattisina, R., and Verrecchia, E. P. 2006. Translation of energy into morphology: Simulation of stromatolite morphospace using a stochastic model. Sedimentary Geology, 185:185-203.

Dupraz, C., Visscher, P. T., Baumgartner, L. K., and Reid, R. P. 2004. Microbemineral interactions: early carbonate precipitation in a hypersaline lake (Eleuthera Island, Bahamas). Sedimentology, 51:745-765.

Farlow, J. O. 1992. Sauropod tracks and trackmarkers: Integrating the ichnological and skeletal record. Zubia, 10:89-138.

Fornós, J. J., Bromley, R. G., Clemmensen, L. B., and Rodríguez-Perea, A. 2002. Tracks and trackways of Myotragus balearicus Bate (Artiodactyla, Caprinae) in Pleistocene aeolianites from Mallorca (Balearic Islands, western Mediterranean). Palaeogeography, Palaeoclimatology, Palaeoecology, 180:277-313.

Freytet, P. 2003. Analyse d'un exemple de fossilisation d'une trace de pas de dinosaure (Lias inférieur des Causses). Le Naturaliste Vendéen, 3:6367.

Gaillard, C., Bernier, P., and Gruet, Y. 1994. Le lagon d'Aldabra (Seychelles, Océan Indique), un modèle pour le paléoenvironnement de Cerin (Kimméridgien supérieur, Jura méridional, France). Géobios, Mémoire spécial, 16:331-348.

Gatesy, S. M. 2003. Direct and indirect track features: What sediment did a dinosaur touch? Ichnos, 10:91-98.

Gatesy, S. M., Middleton, K. M., Jenkins, F. A. Jr and Shubin, N. H. 1999. Threedimensional preservation of foot movements in Triassic theropd dinosaurs. Nature, 399:141-144.

Gerdes, G. and Krumbein, W. E. 1987. Biolaminated deposits. Lecture Notes in Earth Sciences. Springer Verlag, Berlin, 9: 192p.

Gerdes, G. and Krumbein, W. E. 1994. Peritidal potential stromatolites-a synopsis. In Bertrand-Sarfati, J. and Monty, C. (eds.), Phanerozoic Stromatolites II. Kluwer Academic Publishers, Dordrecht, p. 101-129.

Gerdes, G., Claes, M., Dunaitschik-Piewak, K., Riege, H., Krumbein, W. E., and Reineck, H.-E. 1993. Contribution of microbial mats to sedimentary surface structures. Facies, 29:61-74.
Gerdes, G., Klenke, T., and Noffke, N. 2000. Microbial signatures in peritidal siliciclastic sediments: a catalogue. Sedimentology, 47:279-308.

Gerdes, G., Krumbein, W. E., and Reineck, H.-E. 1991. BiolaminationsEcological versus depositional dynamics. In Einsele, G., Ricken, W. and Seilacher, A. (eds.), Cycles and events in stratigraphy. Springer-Verlag, Berlin, p. 592-607.

Ginsburg, R. N. and Hardie, A. H. 1975. Tidal and storm deposits, northwestern Andros Island, Bahamas. In Ginsburg, R.N. (ed.), Tidal deposits. Springer Verlag, Berlin, Heidelberg, New York, p. 202-208.

Ginsburg, R. N., Hardie, L. A., Bricker, O. P., Garrett, P., and Wanless, H. R. 1977. Exposure index: a quantitative approach to defining position within the tidal zone. In Hardie, L. A. (ed.), Sedimentation on the modern carbonate tidal flats of northwest Andros Island, Bahamas. The Johns Hopkins University Studies in Geology, 22: 7-11.

Gregg, J. M., Howard, S. A. and Mazzullo, S. J. 1992. Early diagenetic recrystallization of Holocene ( $<3000$ years old) peritidal dolomites, Ambergris Cay, Belize. Sedimentology, 39:143-160.

Hardie, L. A. (ed.) 1977. Sedimentation on the modern carbonate tidal flats of northwest Andros Island, Bahamas. The Johns Hopkins University Studies in Geology, 22: 202p.

Hardie, L. A. and Ginsburg, R. N. 1977. Layering: the origin and environmental significance of lamination and thin bedding. In Hardie, L. A. (ed.), Sedimentation on the modern carbonate tidal flats of northwest Andros Island, Bahamas. The Johns Hopkins University Studies in Geology, 22: $50-123$.

Henderson, D. M. 2006. Simulated weathering of dinosaur tracks and the implications for their characterization. Canadian Journal of Earth Sciences, 43:691-704.

Hitchcock, E. 1858. Ichnology of New England. A report on the sandstone of the Connecticut Valley, especially its fossil footmarks. Natural Sciences of America Reprint. Boston, Arno Press, 220p.

Kendall, C. G. St. C. and Skipwith, P. A. d'E. 1968. Recent algal mats of a Persian Gulf lagoon. Journal of Sedimentary Petrology, 38:1040-1058.

Krumbein, W. E. and Cohen, Y. 1977. Primary production, mat formation and lithification: contribution of oxygenic and facultative anoxygenic Cyanobacteria. In Flügel, E. (ed.), Fossil algae-recent results and developments. Springer Verlag, Berlin, p. 37-56.

Krumbein, W. E., Cohen, Y., and Shilo, M. 1977. Solar Lake (Sinai). Stromatolitic cyanobacterial mats. Limnology and Oceanography, 22:635-656.

Krumbein, W. E., Paterson, D. M., and Zavarzin, G. A. 2003. Fossil and recent biofilms a Natural history of life on earth. Kluwer Academic Publishers, Dordrecht, 504p.

Kvale, E. P., Johnson, G. D., Mickelson, D. L., Keller, K., Furer, L. C., and Archer, A. W. 2001. Middle Jurassic (Bajocian and Bathonian) dinosaur megatracksites, Bighorn Basin, Wyoming, U.S.A. Palaios, 16:233-254.

Laporte, L. F. and Behrensmeyer, A. K. 1980. Tracks and substrate reworking by terrestrial vertebrates in Quarternary sediments of Kenya. Journal of Sedimentary Petrology, 50:1337-1346.

Levit, G. S. and Krumbein, W. E. 2003. Is there an adequate terminology of biofilms and microbial mats? In Krumbein, W. E., Paterson, D. M. and Zavarzin, G. A. (eds.), Fossil and recent biofilms a natural history of life on earth. Kluwer Academic Publishers, Dordrecht, p. 333-341.

Lockley, M. G. 1991. Tracking dinosaurs: A new look at an ancient world. Cambridge University Press, Cambridge, 238p.

Lockley, M. G. and Hunt, A. P. 1995. Dinosaur tracks and other fossil footprints of the Western United States. Colombia University Press, New York, 338p.

Lockley, M. G. and Meyer, C. A. 2000. Dinosaur tracks and other fossil footprints of Europe. Columbia University Press, New York, 321p.

Lockley, M. G., Holbrook, J., Hunt, A. P., Matsukawa, M., and Meyer, C. A. 1992. The dinosaur freeway: A preliminary report on the Cretaceous megatracksite, Dakota Group, Rocky Mountain Front Range and High Plains, Colorado, Oklahoma and New Mexiko. In Flores, R. M. (ed.), Mesozoic of the Western Interior: Abstracts SEPM (Society for Sedimentary Geology) Theme Meeting, 17.-19.08.1992, Ft. Collins, CO, p. 347-365. 
Lockley, M. G., Kim, J.-Y., and Roberts, G. 2007. The Ichnos project: A re-evaluation of the hominid track record. In Lucas, S. G., Spielmann \& Lockley, M.G. (eds.), Cenozoic Vertebrate Tracks and Traces. New Mexico Museum of Natural History and Science Bulletin, 42: 79-89.

Logan, B. W., Hoffman, P., and Gebelein, C. D. 1974. Algal mats, cryptalgal fabrics and structures, Hamelin Pool, Western Australia. In Logan, B. W. (ed.), Evolution and diagenesis of Quaternary carbonate sequences, Shark Bay, Western Australia. AAPG (American Association of Petroleum Geologists) Memoir, 22: 140-194.

Manning, P. L. 2004. A new approach to the analysis and interpretation of tracks: examples from the Dinosauria. In McIlroy, D. (ed.), The application of ichnology to palaeoenvironmental and stratigraphical analysis. Geological Society of London Special Publication, 228: 93-128.

Marty, D. 2005. Sedimentology and taphonomy of dinosaur track-bearing Plattenkalke (Kimmeridgian, Canton Jura, Switzerland). Zitteliana, B26: p. 20.

Marty, D. 2008. Sedimentology, taphonomy, and ichnology of Late Jurassic dinosaur tracks from the Jura carbonate platform (Chevenez — Combe Ronde tracksite, NW Switzerland): Insights into the tidal-flat palaeoenvironment and dinosaur diversity, locomotion, and palaeoecology. Ph.D. Thesis University of Fribourg (Switzerland), GeoFocus, 21:278p.

Marty, D., Meyer, C. A., and Billon-Bruyat, J.-P. 2006. Sauropod trackway patterns expression of special behaviour related to substrate consistency? An example from the Late Jurassic of northwestern Switzerland. Hantkeniana, $5: 38-41$.

Mazzullo, S. J., Reid, A. M., and Gregg, J. M. 1987. Dolomitization of Holocene Mg-calcite supratidal deposits, Ambergris Caye, Belize. Geological Society of America Bulletin, 98:224-231.

McKeever, P. J. and Haubold, H. 1996. Reclassification of vertebrate trackways from the Permian of Scotland and related forms from Arizona and Germany. Journal of Paleontology, 70:1011-1022.

Medhioub, K. and Perthuisot, J.-P. 1981. The influence of peripheral sabkhas on the geochemistry and sedimentology of a Tunisian lagoon: Bahiret El Biban. Sedimentology, 28:679-688.

Milàn, J. 2006. Variations in the morphology of emu (Dromaius novaehollandiae) tracks reflecting differences in walking pattern and substrate consistency: ichnotaxonomic implications. Palaeontology, 49:405420.

Milàn, J. and Bromley, R. G. 2006. True tracks, undertracks and eroded tracks, experimental work with tetrapod tracks in laboratory and field. Palaeogeography, Palaeoclimatology, Palaeoecology, 231:253264.

Milàn, J., Christiansen, P., and Mateus, O. 2005. A three-dimensionally preserved sauropod manus impression from the Upper Jurassic of Portugal: implications for sauropod manus shape and locomotor mechanics. KaupiaDarmstätter Beiträge zur Naturgeschichte, 14:47-52.

Milàn, J., Clemmensen, L. B., and Bonde, N. 2004. Vertical sections through dinosaur tracks (Late Triassic lake deposits, East Greenland)—undertracks and other subsurface structures revealed. Lethaia, 37:285296.

Monty, C. L. V. 1972. Recent algal stromatolitic deposits, Andros Island, Bahamas, preliminary report. Geologische Rundschau (International Journal of Earth Sciences), 62:742-783.

Nadon, G. C. 2001. The impact of sedimentology on vertebrate track studies. In Tanke, D.H. and Carpenter, K. (eds.), Mesozoic vertebrate life. Indiana University Press, Bloomington, p. 395-407.
Noffke, N., Gerdes, G., Klenke, T., and Krumbein, W. E. 2001. Microbially induced sedimentary structures indicating climatological, hydrological and depositional conditions within recent and Pleistocene coastal facies zones (Southern Tunisia). Facies, 44:23-30.

Padian, K. and Olsen, P. E. 1984. The fossil trackways Pteraichnus: not pterosaurian, but crocodilian. Journal of Paleontology, 58:178-184.

Paik, I.-S., Kim, H.-J., and Lee, Y.-I. 2001. Dinosaur track-bearing deposits in the Cretaceous Jindong Formation, Korea: occurrence, palaeoenvironments and preservation. Cretaceous Research, 22:79-92.

Peabody, F. E. 1959. Trackways of living and fossil salamanders. University of California Publications in Zoology, 63:1-72.

Phillips, P. L. Jr., Ludvigson, G. A., Joeckl, R. M., Gonzalez, L. A., Brenner, R. L., and Witzke, B. J. 2007. Sequence stratigraphic controls on synsedimentary cementation and preservation of dinosaur tracks: example from the Lower Cretaceous, (Upper Albian) Dakota Formation, southeastern Nebraska, U.S.A. Palaeogeography, Palaeoclimatology, Palaeoecology, 246:367-389.

Platt, B. F. and Hasiotis, S. T. 2006. Newly discovered sauropod dinosaur tracks with skin and foot-pad impressions from the Upper Jurassic Morrison Formation, Bighorn Basin, Wyoming, U.S.A. Palaios, 21:249-261.

Porada, H., Bouougri, E., and Ghergut, J. 2007. Hydraulic conditions and matrelated structures in tidal flats and coastal sabkhas. In Schieber, J., Bose, B. K., Eriksson, P. G., Banerjee, S., Altermann, W. and Catuneau, O. (eds.), Atlas of microbial mat features preserved within the clastic rock record. Elsevier, Amsterdam, 258-265.

Rankey, E. C., Enos, P., Steffen, K., and Druke, D. 2004. Lack of impact of hurricane Michelle on tidal flats, Andros Island, Bahamas: integrated remote sensing and field observations. Journal of Sedimentary Research, 75:654-661.

Roehl, P. 1967. Stony Mountain (Ordovician) and Interlake (Silurian) facies analogs of recent low energy marine and subaerial carbonates, Bahamas. AAPG (American Association of Petroleum Geologists) Bulletin, 51:1979-2032.

Schieber, J., Bose, B. K., Eriksson, P. G., Banerjee, S., Altermann, W. and Catuneau, O. (eds.). 2007. Atlas of microbial mat features preserved within the clastic rock record. Elsevier, Amsterdam, 324p.

Scott, J. J., Renaut, R. W., Owen, R. B., and Sarjeant, W. A. S. 2007. Biogenic activity, trace formation, and trace taphonomy in the marginal sediments of saline, alkaline lake Bogoria, Kenya Rift Valley. In Bromley, R. G., Buatois, L. A., Mángano, G., Genise, J. F. and Melchor, R. N. (eds.), Sedimentorganism interactions: a multifaceted ichnology. SEPM Special Publication, 88: 311-332.

Scrivner, P. and Bottjer, D. 1986. Neogene avian and mammalian tracks from Death Valley National Monument, California: their context, classification and preservation. Palaeogeography, Palaeoclimatology, Palaeoecology, 57:285-331.

Thulborn, T. 1990. Dinosaur tracks. Chapman and Hall, London, 410 pp.

Thulborn, T. and Wade, M. 1989. A footprint as a history of movement. In Gillette, D. D. and Lockley, M. G. (eds.), Dinosaur tracks and traces. Cambridge University Press, Cambridge, p. 51-56.

Tucker, M. E. and Burchette, T. P. 1977. Triassic dinosaur footprints from South Wales: Their context and preservation. Palaeogeography, Palaeoclimatology, Palaeoecology, 22:195-208.

Uchman, A. and Pervesler, P. 2006. Surface Lebensspuren produced by amphipods and isopods (crustaceans) from the Isonzo Delta tidal flat, Italy. Palaios, 21:384-390. 